\title{
The Concept of Fitness for Purpose of Goods in Malaysian Today's Online Contract: Issues and Challenges
}

\author{
Farhanin binti Abdullah Asuhaimi ${ }^{1, *}$ Zuhairah Ariff binti Abd Ghadas ${ }^{2}$, Nazli \\ Ismail Nawang ${ }^{3}$, Norhasliza binti Ghapa ${ }^{4}$ \\ 1,2,3,4 University Sultan Zainal \\ *Corresponding author. Email: farhanin@unisza.edu.my
}

\begin{abstract}
The advanced technology and the user-friendly features of many e-commerce websites in Malaysia make many Malaysian consumers opt to buy their necessities using online platforms rather than the traditional face-to-face method. When the Prime Minister made an announcement of the Movement Control Order as a preventive step, consumer's behavior has rapidly changed where e-commerce become their main preference to shop their basic necessities. Thus, the online platform needs to make some reasonable steps to ensure all the sellers comply with the requirement of fitness for the purpose of the product bought by the buyer. This paper highlights the principles of fitness for purpose of goods in Section 16 (1) (a) of Malaysian Sale of Goods Act 1979 and the consequence of the breach based on systematic literature review. This paper also investigates the application of implied terms as to the fitness for purpose of goods in online platforms using the content analysis method. Some tips in buying goods through the online platform and the suggestions to the online platforms to ensure the practice is consistent with the current law in Malaysia are also included in this paper.
\end{abstract}

Keywords-Consumer, Fitness for Purpose, Implied Term, Online Contract, Sale of Goods

\section{INTRODUCTION}

The condition has been defined as a stipulation essential to the primary purpose of the contract (as stated in Section 12 of Malaysian Sale of Goods Act 1979 (SOGA), and in the case of a breach, the aggrieved party has the right to repudiate the contract and has no obligation to perform the contract. If payment has been made, the aggrieved party can recover the price and even entitle to damages for breach of the contract. Condition in a contract can be categorized into the express condition and implied condition. According to McKendrick and Anson, the express condition is the agreed terms specified and agreed by both contracting parties in a contract, and the statement has been inserted without any force from the third party. This type of term may be in the form of oral, writing, or both.

Conversely, the implied condition is a term in a legal agreement that the parties assumed into the contract to prevent the non-performance of the contractual obligations by the contracting parties. It became a condition because of the parties' intention inferred from their conduct other than words. The implied condition has been discussed in the Malaysian Sale of Goods Act 1979 (SOGA) in several sections, including the provision on the requirement of fitness of goods for purpose. Section 16 (a) of SOGA stated that the goods must fit for the buyer's purpose.

In Malaysia, Shopee, with 47,332.8 million traffic monthly visits as of the $4^{\text {th }}$ quarter of 2020 , becomes the first e- marketplace chosen by Malaysians, followed by Lazada with $14,777.07$ million traffic monthly visits. Thus, this conceptual analysis paper will analyse the concept of fitness of the goods as to the purpose it was bought in these two online platforms and discusses three relevant issues in the fitness of goods, namely (a) the concept of fitness of goods for purpose in the sale of goods contract (b) the consequence of goods which does not fit the purpose it was bought in a sale of goods contract and; (c) the concept of fitness of goods for purpose in Shopee and Lazada. 


\section{METHODS}

This article employs a doctrinal analysis where the data locates the law in legislation, decided cases, journal article and books. Library and online database research are to examine the concept of fitness of goods for purpose and the consequence if the goods is not fit for the purpose it was bought.. Shopee and Lazada are the two platforms used as samples in this article to show the practice of fitness of goods for purpose, as highlighted in SOGA. Reference was also made to the terms and policy in Shopee and Lazada on the fitness of goods for purpose.

\section{RESULTS AND DISCUSSION}

\subsection{Implied Condition As To The Fitness Of Goods For The Purpose}

\section{1 .1. The Concept Of Implied Condition To Fitness Of Goods For Purpose}

Section 16(1) SOGA discusses the implied condition as to quality and fitness and reads as below:

Subject to this Act and of any other law for the time being in force, there is no implied warranty or condition as to the quality or fitness for any particular purpose of goods supplied under a contract of sale, except as follows-Where the buyer, expressly or by implication, makes known to the seller the particular purpose for which the goods are required, to show that the buyer relies on the seller's skill or judgment, and the goods are of a description which it is in the course of the seller's business to supply (whether he is the manufacturer or producer or not) there is an implied condition that the goods shall be reasonably fit for such purpose;

Provided that, in the case of contract for the sale of a specified article under its patent or other trade name, there is no implied condition as to its fitness for any particular purpose.

Generally, there is no implied warranty or condition as to the fitness of goods for any particular purpose of goods supplied in a contract of sale because of the common law rule that 'let the buyers be aware of the terms of the contract' under the caveat emptor principle. The buyer is expected to exercise care in making any purchases in concluding any contract. However, there are exceptions to this rule as laid down in Section 16(1) (a) and (b), that the goods must be reasonably fit for purposes for which the buyer wants them and the goods must be of merchantable quality. Nonetheless, for this paper, the authors will only focus on the first part of Section 16(1) (a), which are the goods must be fit for the purposes for which they were bought.
The case of Master Jaya Environmental Sdn Bhd $v$ Pentas Flora Sdn Bhd [2020] 2 CLJ 609 can be a good example to illustrate the application of this concept when Kamaludin Md Said JCA held that Scrubber No 8 was not fit for the purpose under Section 16 of the SOGA because it cannot be used as an air pollution control device. It became useless for the purpose it was bought as Malaysian Department of Environment suspended it and eventually they had to replace it with the equipment from China. Thus, it was clear that Scrubber No 8 could not control bad odor pollution and failed to function as an air pollution control device, and breach section 16 of the SOGA.

The three express preconditions and the proviso of Section 16 (1) (a) had also been highlighted by Zakaria Yatim $\mathrm{J}$ in Union Alloy (M) Sdn Bhd $v$ Syarikat Pembenaan Yeoh Tiong Lay Sdn Bhd [1993] 2 AMR 2012 which are; firstly, the buyer must make known to the seller the particular purpose for which the goods are required; secondly, it must be shown that there was reliance by the buyer in the seller's skill and judgment, and the buyer must rely on the seller to supply suitable goods; thirdly, the goods must be of a description which it is in the course of the seller's business to supply; and lastly the proviso if the goods are specific, they must not be sold under their patent or trade name.

In this case, the plaintiff sold a hoist, a machine used to raise workers onto buildings' higher floors or roofs. The machine was failed to stop at the intended height while it was used to transport two workers to the $21^{\text {st }}$ floor of the building under construction. Consequently, the machine crashed to the ground, causing one workman's death and severe injuries to the other. The plaintiff sued for the balance of payment, but the defendant alleged that the plaintiff was in breach of the fitness condition for the purpose implied under section 16(1) (a) SOGA. The court, upon examining the breach of section 16(1) (a), stated that, for precondition one, the particular purpose for which the goods were required might be express or implied, and in this case, the purpose of the hoist was required was implied as it has only one purpose, vertical transportation of men and materials at the worksite and the court found that the accident could also have been caused by improper installation of the machine by the defendant, by an additional 30 meters to a height of 55 meters. However, there was no evidence to suggest that the said machine was not fit for its sole purpose.

The above case has elaborated precisely on the first precondition: the buyer must tell the seller the particular purpose for which the goods are required. But, a question arose on whether the goods must fit a particular purpose or range of purposes. Collins MR in Priest v Last [1903] 2 KB 148 stated that:

The fact that, by the very terms of the sale itself, the 
article sold purports to be for use for a particular purpose cannot possibly exclude the case from the rule that, where goods are sold for a particular purpose, there is an implied warranty that they are reasonably fit for that purpose. The sale is of goods which, by the very description under which they are sold, appear to be sold for a particular purpose.

It means that the buyer must make known to the seller the specific purpose for which he requires the goods so that the seller can supply the goods to meet his purpose. The seller can reasonably exercise his skill or judgment to select from the goods he dealt when he obtained sufficient particulars to buy the goods. To do this, the seller needs to identify the characteristics of the goods that will enable them to meet the buyer's purpose. If the purpose of the goods is evident, there is no need to specify the purpose. But, when the buyer merely indicates a range of possible purposes for which he requires the goods, he does not furnish the seller with sufficient information from which the seller can identify the characteristics of the goods of the kind that will satisfy the buyer's need. Thus, in this case, section 16 (1) (a) is not engaged, and the seller will not be liable for supplying the goods that do not meet the purpose of which the goods were required. Moreover, the word 'purpose' used in Section16 (1) (a) in the singular excludes the goods having to satisfy more than one purpose or a range of purposes.

However, if the buyer expressly makes known to the seller that he requires goods for a range of purposes and expressly informs the seller that he is relying on the seller to furnish him with goods which is fit for that range of purposes, the goods supplied must be fit for the range of purposes as desired by the buyers (Ashington Piggeries Ltd \& Anor $v$ Christopher Hill Ltd [1972] AC 441 at 507).

Concerning the second precondition in Union Alloy's case, the learned trial in the case of Khong Seng v Ng Teong Kiat Biscuit Factory Ltd [1963] 1 MLJ 388 who had relied on the judgment of Lord Rusell CJ in Gillespie Brothers \& Co v Cheneye Rdgar \& Co [1896] 2 QB 59 upheld that mere disclosure of a purpose may amount to sufficient evidence reliance on the skill and judgment of the seller. The court also picked the words of Lord Buckmaster in Manchester Liners Ltd $v$ Rea Ltd [1922] 2 AC 74 at 79 to support their decision where it stated that:

If goods ordered for a special purpose, and that purpose is disclosed to the vendor, so that in accepting the contract he undertakes to supply goods which are suitable for the object required, such contract is, in my opinion, sufficient to establish that the buyer has shown that he relies on the seller's skill and judgment.

Thus, the court believes that there is reliance on the plaintiff's skill and judgment when the purpose of the tallow was made clear to the plaintiff.

In Pekat Teknologi Sdn Bhd v Novaris Pty Ltd \& Anor [2014] AMEJ 1563, the plaintiff brought an action against the first and second defendants for the losses it suffered arising from the faulty Novaris surge protective devices (SPD) supplied by the defendants. The plaintiff emphasized in its claim that the second defendant, a company incorporated in Malaysia, manufactured and sold Novaris SPDs in Malaysia knew the purpose for which it had purchased the Novaris SPDs, and it had relied on the skill and judgment of the second defendant to supply suitable devices. In the judgment, the court held that the plaintiff had satisfied the court that it relied on the second defendant's skill and judgment to supply Novaris SPDs that meet with the purpose of it was bought. Thus, the defendants, in this case, had breached Section 16 SOGA.

In explaining the third precondition, reference can be made to Sunrise Sdn Bhd v L \& M Agencies Sdn Bhd's case 3 MLJ 544, where the learned trial judge was satisfied that there is a case under Section 16 of the Act and highlighted that:

To my mind it is nothing more than common sense. If the defendant knows the purpose for which the plaintiff needs the particular goods, then it is clear that the plaintiff is relying on the seller's skill and judgment to supply the suitable goods to cater for the particular purpose for which the goods were required. There is no doubt in my mind that the defendant well knew that the second plaintiff wanted the tower cranes to facilitate the construction of the condominium tower blocks at the project. The defendant also well knew that the sole purpose of the tower cranes was the vertical transportation of materials and equipment to the upper construction site to facilitate the building of the tower blocks.

It was admitted that the defendant was in the business of selling tower cranes during the transaction was made. Thus, the third precondition is fulfilled.

The application of the fourth precondition and proviso of Section 16 (1) (a) SOGA was clarified by the Court of Appeal in Medicon Plastic Industries Sdn Bhd v Syarikat Cosa Sdn Bhd (1995) 2 MLJ 257 where the defendant, in this case, relied on the proviso to Section 16 (1) stated that the contract for the sale of each of the machines was for a specified article under its patent or trade name. The Lordship referred to Benjamin's Sale of Goods to clarify on the proposition that the cases restricted the proviso to the point where it only applied if an article was ordered by its trade name and in the books, case Baldry v Marshall [1925] $1 \mathrm{~KB} 260$ was also cited where Bankes LJ suggested the test for the operation of the proviso as follows;

did the buyer specify it under its trade name in such a way as to indicate that he is satisfied, rightly or 
wrongly, that it will answer his purpose, and that he is not relying on the skill or judgment of the seller, however great the skill or judgment maybe?

In addition to that, Sargant LJ in Baldry's case said:

It seems to me that the articles which are dealt with in that proviso are primarily things like patent medicines and common articles sold under wellknown trade names. In my judgment, the proviso does not apply to an article like a motor car, which is sold under a very elaborate and specific description.

In Sunrise's case, even though the tower cranes sold had a trade name of Yangong-Potain and was also described in the contract by its trade name, it did not exclude the operation of the condition implied by Section 16 (1) (a). In this case, the second plaintiff was familiar with the French-made Potain tower cranes, and since they were informed that these China-made Yangong- Potain cranes were made in China under license, the plaintiff was entitled to assume that the said two cranes were of similar quality.

The proviso section, however, received much criticism for the proviso contained in it. It seems that the proviso provides a defense to the seller who sells a specified article under its patent or other trade names. It means there is no implied condition regarding the fitness of goods for any particular purpose when the buyer buys a goods under its trade name. The proviso was deleted in England, and the Law Commissions, while suggesting the deletion, explained further in their Working Paper No 18 by saying that there are several cases where the buyer had relied on the seller's skill and judgment and not the trade name, make the proviso useless.

\subsubsection{Consequence of Breach}

There is a total failure to perform the contract if the goods supplied do not fit the purpose it was bought since there is a breach of section 16 (1) (a) SOGA. The innocent party, in this case, has a right to repudiate the contract since the breach of condition in the sale of goods contract goes to the substantial part of the contract and claim damages for the breach. In the case of Union Alloy, after hearing all the evidence given by both contracting parties, the court decided that there is a breach of condition of fitness for purpose implied in Section 16 (1) (a), and the contract is terminated, and the plaintiff's claim was awarded for damages.

\subsection{The Concept Of Fitness For Purpose In Malaysian Online Platform}

Many buyers nowadays prefer to buy their necessaries through online platforms since they can buy whatever they want with just one click. They have no worries about the space of parking, the need to fuel their vehicle and cash out their money, and so on. The buyers are also free to choose any products from any online platform to fulfill their needs. However, since the online buyers cannot touch, hold, inspect the products as in the physical shop, it is crucial for the sellers and the online platform to ensure that the transactions meet the buyers' expectations, especially when the buyers have a particular purpose for buying a particular product. A good quality website must present comprehensive information on the products and the sellers, as it may affect the buyer's purchase intention and trust to enter into an online contract. The description of the goods may help the buyers to choose the best goods suit to their purpose of buying.

\subsubsection{Application of Implied Condition as to Fitness for Purpose in Shopee and Lazada}

Shopee helps the buyer by specifying the description, making the seller know the particular purpose for which the goods are required. Shopee makes it compulsory for the seller to fill in the product description and brand attributes before listing products on its platform. Shopee also encouraged the sellers to provide a complete and detailed description to equip shoppers with a better understanding of the product since it may help them make informed decisions and reduce inquiries. Shopee suggests three ways for the sellers to create informative product descriptions; which are first, the sellers must include product specifications by providing buyers with technical product details such as material, weight, dimensions, and other unique factors, and these details are essential for electronics, equipment, and tools, secondly; the seller is encouraged to share the uses and benefits of the product by explaining the product's features and benefits, and show the different ways buyers can enjoy using the product; and lastly, the seller need to specify the product warranties, if applicable. However, there is no required particulars that need to be included in the product description. Shopee only provides ample space under the description heading, allowing the sellers to include any relevant information as to product description. This ample space will lead to unwanted product descriptions since the sellers may put whatever description to the product listing they wish, even though the information may not contribute to the buyers' understanding.

The policy of Lazada does not specify any details in the listing of products specifically, as it only requires the seller to upload the product description using the template provided, for instance, the brand, model, the long description, and the short description of the product. A minimum of one product's image needs to be uploaded together with 50 product description words. The Content Score program was also introduced to guide the seller on making a high standard of product information that may significantly impact the seller's company. 
On the other hand, if the buyer has a specific purpose for buying products, he can utilize the chat tab in the right corner of the Shopee platform or messages tab in the right corner of the Lazada platform to convey his specific purpose of buying to the seller before entering into any contract. Besides that, the buyer in Lazada may also look at the question and answers in each product description for any additional information. If the information needed is not on the website, the buyer may use the box to ask any question, and the seller will respond to the question publicly. For the second precondition, there must be reliance by the buyer on the seller's skill and judgment, and the buyer must rely on the seller to supply the suitable goods. Concerning this, Shopee has introduced the Preferred Sellers campaign to build trust between the shoppers and the sellers. Preferred Sellers is a particular seller which Shopee selects in recognition of their excellent sales and customer service. The shoppers can recognize the preferred sellers by the preferred tag shown in the shops and listings. They are recognized based on their performance in Shopee but not necessarily an expert to the product sold. Thus, it is not easy to prove the seller's knowledge and skill on their advertised product. Nevertheless, Lord Buckmaster in Manchester Liners Ltd, the act of disclosing

The particular purpose to the vendor itself may constitute reliance on the skill and judgment of the seller. Thus, conveying a message on the specific purpose of buying a particular product fulfills this reliance requirement.

In Lazada, a seller may apply to be a LazMall seller if they fulfill all the requirements; which are, the minimum orders per month must reach 300 orders, the seller's account must register for more than six months in the Lazada platform, the rating must be more than $70 \%$, the cancellation rate due to the seller's fault must be less than $2 \%$, the seller rate for being the goods on time is more than $90 \%$, the chat response must be more than $85 \%$, and the return rate must be less than $1 \%$. LazMall is a marketplace that offers products from international and local brand sellers and authorized distributors for customers who want to access a wide range of branded products. Only original and authentic products are being sold on this LazMall platform. It means that the quality of the sellers being recognized as LazMall sellers is higher than the ordinary sellers. As long as the buyer informs the seller of his specific purpose of buying, the element of reliance is complete.

For the third precondition, the goods must be of a description which it is in the course of the seller's business to supply a particular product. In Shopee and Lazada, the sellers may be sellers of a specific product or various products. It is much easier for sellers of a specific product to expect expertise compared to those who sell many types of products. In both online platforms, the seller cannot be traced as being in their course of business to supply unless they describe themselves as one on the seller's front page. There is no other way to recognize the course of the seller's business as nothing in these two platforms asked the sellers to clarify their expertise lawfully. Thus, reliance on the seller's profile on the front page is the only available method.

For the fourth precondition, the product listing in Shopee and Lazada asked about the brand name before the product could be published on the seller's page. The seller needs to fill in the product's brand without including any evidence for clarification. This practice may cause the false product brand to be included in the description to mislead the buyers since the approval of such listing is automatic and not through any verification before publishing. A fake product may be displayed as an original product from its description and a picture attached in the advertisement.

\subsubsection{Consequences of Breach in Malaysian Online Platform}

In Shopee, if the products delivered do not fit with the specific purpose of buying due to the counterfeit products, the buyer has a right to ask for a refund and/or return. Shopee will then review the issue on a case-to-case basis and notify the seller in writing of any updates on the buyer's refund and/ or return. The seller needs to respond to the request within a stipulated time; if no response by the seller, Shopee has the discretionary power to decide. If the buyer opts to return the product, the shipping fee will be borne by the seller if the fault is on the seller, such as the wrong product was delivered to the buyer, but the money will only be refunded after the seller receives the product posted by the buyer. If no response from the seller within 12 days after accepting the posted product, Shopee will refund the buyer without further notice.

Similarly, in Lazada, the buyer can initiate the returns process if the goods delivered do not fit the purpose of the buyer's buying by clicking the 'Return' button at the buyer's order. Lazada, in its policy, tabled some checklist on the return and refund policy, and it can be seen in the following table; 


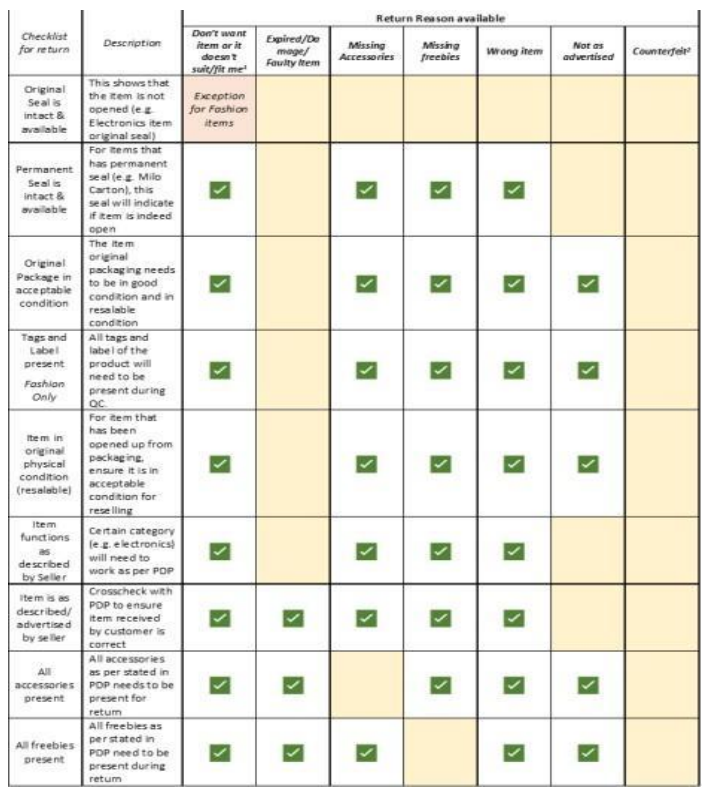

Figure 1: Checklist on return and

refund in Lazada The buyer also needs to include the reason and the picture

for returning or asking for a refund. The notification will be given to the seller and the seller within three days to respond to the request. If there is no response from the seller, an auto refund will be given to the buyer. In the case if the seller is responded to the request, there are four possibilities after the notification received by the seller; 1 ) if the seller accepts the request and ask or the buyer to return the product, then the buyer needs to return the product within 7-14 days (depends on the product you purchased) to the seller or Lazada, 2) if the seller accepts the request and asks the buyer to retain the product, then the buyer will get a refund from the seller, 3) if the seller agrees to refund the buyer partially and the buyer retains the product, then the buyer is entitled to the partial refund, and 4) if the seller rejects the request, then the buyer needs to make a complaint directly to Lazada to discuss on the issue, and Lazada will review the case, and a decision will be given after three days.

The terms and policies laid down in Shopee and Lazada are clearly against Section 12 (2) SOGA, wherein SOGA, the consequence of the breach of implied terms, may give rise to the innocent party to repudiate the contract, but in these two online platforms, the contract can only be rescinded, and the innocent party may be awarded remedies if necessary. Moreover, the absolute power of the contract's termination is given to the shopping platform to decide within their discretionary power to accept the request for the money refund and/or return of the product. The practice of Shopee and Lazada, however, does not go against the law since Section 62 of the SOGA allows the exclusion of the implied terms and conditions by express agreement as the section reads as follows;
Where any right, duty, or liability would arise under a contract of sale by implication of law, it may be negatived or varied by express agreement or by the course of dealing between the parties, or by usage, if the usage is such as to bind both parties to the contract.

Therefore, it is clear that the sellers are allowed to exclude all the implied terms in SOGA to restore the contractual freedom of the contracting parties in such a contract, especially the sellers, as they are in the dominant position in the sale of goods transaction. However, the sellers' terms should follow the principles laid down in the exclusion clause as it is usually inserted to restrict or limit the liability, duty, or remedy that arises from a legal relationship of the contracting parties. The contracting out provision may harm the buyers, who are typically at a weak and vulnerable position in a contract. Moreover, the principle of contra proferentum rule is applicable when there is any doubt on the meaning and scope of the exemption clause. When the matter is brought to the court, the judge will resolve the meaning against the party who inserted it and now relies on it (Rutler $v$ Palmer [1922] 2 KB 8).

It is then crucial for the buyer to take extra caution when entering into any traditional or online contract. The maxim of caveat emptor is always become an essential principle to be discussed in the online contract. Shopee has taken some cautions when introducing the Shopee Guarantee campaign, where the campaign may give a clear guideline for the buyers and sellers on how the transactions in Shopee are conducted and the buyers' rights when there is a dispute on the product advertised.

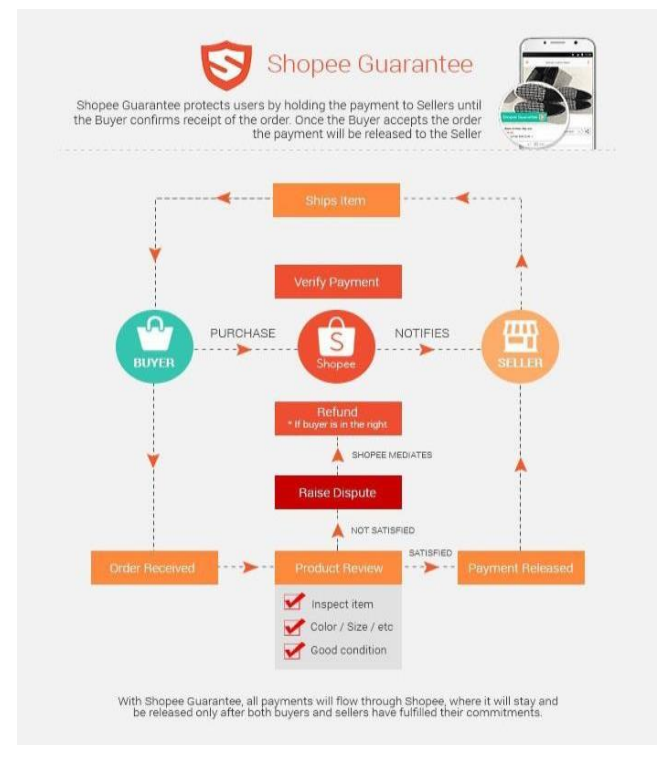

Figure 2: Shopee Guarantee Policy 
Lazada, on the other hand, introduced LazMall Guaranteed Delivery, a fast delivery service for selected LazMall products. If the product is delayed (beyond the delivery promise time), a compensation rebate will be given to the buyer's Lazada Wallet within 24 hours from the delivered status.

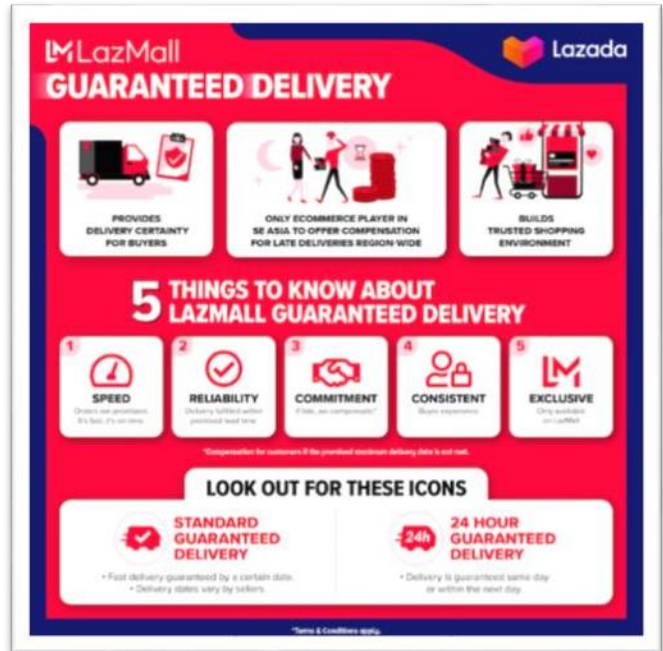

Figure 3: LazMall Guaranteed Policy

\section{CONCLUSION}

In conclusion, it is suggested that the sellers should comply with the terms in SOGA regarding breach of condition in contract by giving the right to terminate the contract if the products do not fit with the specific objectives of the buyer when bought the product. The buyer should return the product to the seller, and the seller must pay the price that the buyer paid for the product. The seller should also bear the shipping cost as compensation in the case of breach of condition.

Besides that, as the principle caveat emptor and contractual freedom following the doctrine of laissezfaire become a superior principle underlying in every sale of goods contract. As an online buyer who cannot meet the seller and inspect the product face-to-face, the buyer is responsible for protecting themselves. It is essential to read the description carefully, chat with the seller if necessary, and take a picture when received the product. A complaint without a picture is complex for the refund process. Buying in Lazada or Shopee is much safer than buying direct with the seller through other platforms; however, the buyer always needs extra caution on the relevant policy highlighted in the platform. Failure to follow the guideline stated in the platform may amount to the self-ignorance of the rule.

\section{REFERENCES}

[1] Abdul Rahman, Nur Rabiatuladawiah. "The Rise and Fall of Caveat Emptor in Malaysian Sale of
Goods Contract." Journal of Law \& Governance 1, no. 1 (2018): 1-14.

[2] Abdul Razak, Farihana, Z. A. Abd Ghadas, Farhanin Abdullah Asuhaimi, and Nurzihan Mohammad Udin. "Unfair Contract Terms in Online Contracts: Special Reference To Online Booking of Flight Tickets." Hamdard Islamicus 43, no. 2 (2020): 230-36. https://www.researchgate.net/publication/34432 4532.

[3] Abdullah Asuhaimi, Farhanin, Zuhairah Ariff Abd Ghadas, Nur Amani Pauzai, and KhairunNisaa Asari. "Legal Issues Relating to Online Transaction: Special Reference to Children Product Safety in Malaysia." International Journal of Academic Research in Business and Social Sciences, 2019. https://doi.org/10.6007/ijarbss/v9-i3/5699.

[4] Abdullah, Farhah, Sakina Shaik, and Ahmad Yusoff. "Legal Treatment of Exclusion Clauses in Consumer Contracts in Malaysia," no. October 2015 (2016).

[5] Ahmad Yusoff, Sakina Shaik, Shamsuddin Suhor, Rahmah Ismail, Azimon Abdul Aziz, Muhammad Rizal Razman, and Kartini Aboo Talib@Khalid. "Consumer's Right to Redress against Traders under the Law of Supply of Goods: A Comparative Study of Selected Jurisdictions." In Journal of Global Management, 2:2106-23, 2011.

[6] Alsagoff, Syed Ahmad. Principle of the Law of Contract in Malaysia. 4th Edition. Malaysia: Lexis Nexis Malaysia Sdn Bhd, 2015.

[7] Amin, Naemah, and Roshazlizawati Mohd Nor. "E- Consumer Protection in a Contract for the Sale of Goods: A Malaysian Perspective." International Journal of Digital Society 4, no. 2 (2013): 798-805.

[8] Beatson, Jack, Andrew Burrows, and John Cartwright. Anson's Law of Contract. 29th ed. New York: Oxford University Press Inc, 2010.

[9] Corbin, Arthur L. "Conditions in the Law of Contract." The Yale Law Journal 28, no. 8 (1919): https://doi.org/10.2307/787276.

[10] Francis M. Burdick. "Conditions and Warranties in the Sale of Goods." Columbia Law Review 1, no. 2 (1901): 71-93.

[11] Lazada. "How Do I Apply to Become LazMall Seller?," 2019. https://sellercenter.lazada.com.my/seller/helpce nter/how- do-i-apply-to-become-a-lazmallseller-8582.html.

[12] Lazada Seller Centre. "Terms of Use." Lazadazada, 2020. https://www.lazada.com.my/terms-of-use/.

[13] McKendrick, Ewan. Contract Law. 12th editions. London: Macmillan Education and Palgrave, 2017.

[14] Muller, J. "Malaysia: Top 10 e-Commerce Sites in Malaysia Q4 2020, by Monthly Traffic," 2021. https://www.statista.com/statistics/869640/mala ysia-top-10-e-commerce-sites/.

[15] Nabi Baksh, Abdul Majid, and Krishnan Arjunan. Sale of Goods Law in Malaysia. 1st ed. Selangor, Malaysia: Thomson Reuters Malaysia Sdn Bhd, 2016.

[16] Nabi Baksh, Abdul Majid, and Krishnan 
Arjunan. Contract Law in Malaysia. 2nd ed. Petaling Jaya, Selangor: Lexis Nexis, 2008.

[17] Peel, Edwin, and Guenter Treitel. Treitel the Law of Contract. 14th editions. London: Sweet \& Maxwell, 2015.

[18] Richards, Paul. Law of Contract. 13h edition. Harlow: Pearson Education Limited, 2017. www.pearsoned.co.uk/legalupdates.

[19] S Santhana Dass. General Principles of Contract Law. Second Edi. Selangor, Malaysia: Thomson Reuters Malaysia Sdn Bhd, 2017.

[20] Shopee. "Return and Refund Policy." Shopee Mobile Malaysia Sdn Bhd, 2018. https://shopee.com.my/docs/111.

[21] "Writing Informative Product Description." Shopee Seller Hub, 2021. https://seller.shopee.sg/edu/article/87.

[22] Stone, Richard. "The Contents of the Contract." In The Modern Law of Contract, 10th Edition., 233-62. London and New York: Routledge Taylor \& Francis Group, 2013. https://doi.org/10.4324/9781843144854-13.

[23] Vivi Iswanti Nursyirwan, and Sasmita Sari Ardaninggar. "The Factor Analysis That Influence the Student Purchase the Factor Analysis That Influence the Student Purchase Intention in Shopee E-Commerce." Economics and Accounting Journal 3, no. 2 (2020): 118-29.

[24] Lazada. "What Is LazzMall from Lazada?," 2019.

https://sellercenter.lazada.com.my/seller/helpcen ter/what- is-lazmall-from-lazada8591.html?spm=a2a16.helpcentersearch.article.1.30ef4da0t86fXZ.

[25] Shopee Seller Education Hub. "What Is Shopee's Preferred Seller Programme?," 2019.

https://seller.shopee.com.my/edu/article/31

3/What-is- Shopees-Preferred-Seller-

Programme. 